\title{
A mode choice analysis of school trips in New Jersey
}

\author{
Robert B. Noland \\ Rutgers University ${ }^{\mathrm{a}}$
}

\author{
Hyunsoo Park \\ Rutgers University
}

\author{
Leigh Ann Von Hagen \\ Rutgers University
}

\author{
Daniel G. Chatman \\ University of California, Berkeley
}

\begin{abstract}
This paper examines the mode choice behavior of children's travel to school based on surveys conducted at a sample of schools in New Jersey. The main focus is on a variety of network design, land use, and infrastructure variables that have typically been associated with walking activity. Using a mixed logit model, it is found that good connectivity, more intense residential land use, and better sidewalk infrastructure are associated with increased walking to school. The use of a mixed logit model allows the examination of individual heterogeneity. Results indicate substantial heterogeneity in behavior associated with built environment variables.
\end{abstract}

Keywords: Safe routes to school, walking trips, mixed logit

\section{Introduction}

Over the last few decades, the rate at which children walk to school has dropped precipitously. While in 1969 about 40 percent of school trips in the United States were by walking, in 2001 this had dropped to about 13 percent (McDonald 2008, 23-35). Similar reductions in walking to school have been found in other countries (Sirard and Slater 2008, 372). Based on an analysis of the 2001 US National Household Transportation Survey, about half of all students are now driven to school by their parents, even for short distances of under a mile (McDonald 2007, 509-516). Policymakers have recognized that walking to school can account for a significant portion of the physical activity that children engage in over the course of a day and that reduced walking to school may be a cause of high obesity levels in children (McMillan 2005, 440-456). Early travel activity may also be linked to habit formation, affecting how children make travel decisions as adults (McMillan 2005, 440-456), with consequent impacts on the environment. For these reasons, among others, policymakers set a goal of increasing walking trips to school, and in 2005 the reauthorization of federal transportation legislation in the US created the Safe Routes to School program to fund programs run by state transportation departments.

Research in recent years has identified some of the factors associated with walking. These include measures of urban form (such as density of development), land use mix, and urban design (such as the presence of sidewalks) encompassing elements of density, diversity, and design as elucidated by Cervero and Kockelman (1997, 199-219). Recent work has analyzed these factors specifically for school trips. In general, distance or travel time is found to be a critical determinant (McDonald 2008, 23-35; Ewing and Cervero 2001, 87-114; Ewing, Schroeer, and Greene 2004, 55-63; Schlossberg et al. 2006, 337-346; Sidhartan et al. 2011, 78-86; Mitra 2012, 1-23), and this is partly due to newer schools being built at greater distances from where students live. Schools are also built on roads that may not be amenable to walking, and studies have found that measures to represent walkability also affect the

\footnotetext{
a rnoland@rutgers.edu
} 
propensity to walk to school (Ewing and Cervero 2001, 87-114; Ewing, Schroeer, and Greene 2004, 55-63; Schlossberg et al. 2006, 337-346; McMillan 2007, 69-79; Boarnet et al. 2005, 134-140). An analysis of school trips in Toronto, however, found that a walkable built environment around the home had a larger effect than a walkable environment immediately around the school (Mitra, Buliung, and Roorda 2010, 150-159). A recent review documents studies that show both positive and negative correlations of network features (Mitra 2012, 1-23). A study of school travel in Taiwan specified a nested logit model; this model examined whether children traveled independently or were escorted to school (Lin and Chang 2010, 867). Results were broadly similar to other studies in terms of factors that lead to more walking trips or those that discourage walking. Studies have also found that parental concerns, and travel patterns such as driving to work, can influence the decision to drive children to school (McDonald 2008, 324-331; Kerr et al. 2006, 787-794).

A stream of research in urban design has sought to devise indexes for characterizing the beneficial features associated with walking (Frank et al. 2006, 75-87; Frank et al. 2005, 117-125; Frank et al. 2010, 924-933; Saelens and Sallis 2007, 387-395; Manaugh and El-Geneidy 2011, 309-315). Alternatively, design variables that are correlated can also be combined via a principal components analysis (Pinjari et al. 2008, 17-26). Manaugh and El-Geneidy (2011, 309-315) also examined school trips and found that associations with walking were stronger when walkability indexes were composed of network variables rather than those with land use and commercial activities. This latter study points to the difficulties associated with using indexes; namely, it is not possible to separate out the specific built environment feature that most influences walking. Of course, any model that includes highly correlated measures makes inference impossible; thus, the approach we take here is to estimate separate models to isolate specific features associated with walking to school.

Most research on the relationship between urban form and travel to school does not address the taste heterogeneity of decision makers. For example, even if the walking environment is highly conducive to children walking to school, individual preferences (of parents) might lead to some children not walking to school. Using repeated choices-in our case, daily travel reported over a one-week period-and mixed logit estimation allows the estimation of both mean parameter estimates and their standard deviation, thus providing information on individual heterogeneity as well as controlling for it, as opposed to maximum likelihood estimates that provide only a mean parameter estimate for the sample. Mixed logit estimation also avoids problems of the independence of irrelevant alternatives of multinomial logit models.

Our data is derived from 19 schools in New Jersey that comprise a variety of urban and suburban school districts with a wide variation in ethnicity and income. Urban form and walkability around each school also vary, providing a rich data set for analysis. Student travel data was collected via a parental survey, similar to the work of Schlossberg et al. (2006, 337-346) and McMillan (2007, 69-79). Our objective is to estimate models that control for individual heterogeneity in the choice of mode used for school travel. Our results, based on mixed logit estimations, find associations with socioeconomic variables and with some of the urban form and walkability variables commonly found in other studies, providing additional evidence of the importance of good walking environments for encouraging children to walk to school.

\section{Hypotheses}

We examined several hypotheses concerning the mode chosen for traveling to school. We modeled mode choice in a utility-maximizing framework of a discrete choice model, implying that the agent making the choice is rational and seeks to maximize utility. In fact, children may or may not have much 
influence over the choice; in most cases decision making is likely joint with, or dominated by, their parents (McMillan 2005, 440-456).

Alfonzo $(2005,808-836)$ defines a hierarchical framework for how individuals determine whether they will walk to a destination. The first level is determining the feasibility of walking, which can be linked to time constraints and household characteristics that affect time constraints. Second, are accessibility factors — basically, the distance of activities and the infrastructure-available for walking? Third are safety considerations, mainly perceptions of crime and danger, which can be influenced by neighborhood characteristics. Fourth is how various urban design features, from traffic calming to street furniture, make walking more comfortable. Finally, the pleasurability of walking is influenced by aesthetics, diversity of surroundings, public spaces, and activity. It is likely that many of these considerations are correlated and overlap - for example, urban design features affect aesthetics and might make an area seem safer. Time spent walking in a more attractive area may be perceived as less cumbersome.

Considering this framework, the results of other empirical work, and the constraints of our data, hypotheses can be formulated using several key attributes. First, the travel time or distance from home to school likely affects walking more than driving or taking the bus; thus, those who have shorter travel times are more likely to walk. The age of children may also affect their mode choice; older children may be more independent and parents will be less concerned with them walking to school alone. We do not have data on the age of children but instead use their grade level (ranging from pre-kindergarten to $8^{\text {th }}$ grade) and hypothesize that those in higher grades are more likely to walk to school.

We also controlled for parental perceptions of whether walking to school is encouraged by the school. We expect programs that encourage children to walk may result in higher rates of nonmotorized travel; however, this may also be endogenous, as those schools that actively encourage children to walk may also be in an environment where it is more feasible to walk or bicycle.

We also expect household sociodemographic characteristics to affect children's travel behavior. Ethnic groups generally reflect socioeconomic characteristics and their living places-urban or suburban. African American or Hispanic children usually live in urban areas, and their household median incomes are lower than those of white or Asian children. Therefore, we hypothesize that African American or Latino children are more likely to walk to school than other ethnic groups. Data on household income was incomplete and was not used in our analysis.

The relative walkability of the environment around the school is a critical factor that others have found to be associated with increased walking (although less so for bicycling) (Sirard and Slater 2008, 372; McMillan 2005, 440-456). Many of the variables that make an area more walkable tend to make walking more convenient, pleasant, and safer. We specifically look at land-use patterns, sidewalk connectivity and width, traffic speeds, and off-street parking capacity, with the expectation that these will be associated with walking choice. These design variables are the focus of various Safe Route to School infrastructure interventions, so understanding their role is of particular interest. However, we also expect that although these design factors affect mode choice, there is taste variation based on the preferences of parents in how their children travel to school.

\subsection{Survey development and administration}

The survey was developed and managed by staff from the New Jersey Safe Routes to School Resource Center. The goal of the survey was to learn how students travel to school and to gain an understanding of any issues or concerns parents have with allowing their child to walk or bicycle to school. Local communities selected to receive federal funding from the New Jersey Safe Routes to School (SRTS) program are required to collect data on the modes used for getting to school. Of note for our analysis, the survey was not developed with the express goal of performing a mode choice analysis; thus, the analysis is opportunistic in taking advantage of a dataset collected for other purposes. Some of the shortcomings of 
the data are discussed further below.

The survey was based partly on an instrument developed by the National Center for Safe Routes to School, ${ }^{1}$ as well as a survey developed by the SRTS program in Georgia. In June 2007, the survey was pre-tested with a sample group of parents. The pre-test explored question wording and interpretation, desired outcomes, survey distribution timing and collection methods, possible incentive schemes, noncompliance issues, administration issues, and results reporting. ${ }^{2}$

The participation of schools in the survey was voluntary, as was participation by parents; however, school participation was encouraged as part of a statewide evaluation effort. Schools and municipalities that seek federal SRTS funds are asked to provide data on the level of walking and bicycling to school as part of the SRTS funding application process. There is no consistency among school districts or individual school policy on walking and bicycling in New Jersey, and clearly there could be some bias in those that seek SRTS funds. Despite this, some schools in our sample actually prohibit bicycling, ostensibly for safety reasons.

We had data from 19 schools in 10 school districts. These are shown in Table 1 along with the method in which the school distributed the survey, which varied somewhat between school districts. In most cases, English and Spanish versions of the survey were made available.

Figure 1 provides a map of New Jersey showing the spatial distribution of where the schools in our analysis were located.

There was substantial variation in the response rates achieved at each school. This was largely associated with the efforts put in by individual coordinators at each school. Initial contact with the districtlevel coordinator of the SRTS program was usually done; in many cases the coordinator was a volunteer. Direct contact with individual school coordinators was not always allowed, and thus the ability to influence response rates was constrained. In one case—at Dunn Middle School in Trenton—-there was the opportunity to hand out questionnaires directly to parents at a parent-teacher conference, and nearly every parent in attendance completed a survey; however, because of low parental turnout, only 43 surveys were completed out of a student population of 696 .

\footnotetext{
${ }^{1}$ The survey developed by the National Center for Safe Routes to School is available at http://www.saferoutesinfo.org/resources/evaluation_parent-survey.cfm, accessed June 2013.

${ }^{2}$ A copy of our survey instrument, including a Spanish translation, is available from the authors or at http://www.state.nj.us/ transportation/community/srts/pdf/needs_assess.pdf, accessed June 2013.
} 
Table 1: Schools surveyed, with tally of questionnaires obtained and survey method.

\begin{tabular}{|c|c|c|c|c|}
\hline School District / School & $\begin{array}{c}\text { Total } \\
\text { Enrollment }\end{array}$ & \begin{tabular}{|c|} 
Surveys \\
Collected
\end{tabular} & $\begin{array}{c}\text { Grade Levels } \\
\text { Surveyed }\end{array}$ & Survey Method \\
\hline \multicolumn{5}{|c|}{ Freehold Township School District, Monmouth County } \\
\hline Park Avenue Elementary, Freehold & 449 & 148 & $\mathrm{~K}-8$ & Parental backpack survey \\
\hline Learning Center, Freehold & 525 & 148 & $\mathrm{~K}-6$ & Parental backpack survey \\
\hline \multicolumn{5}{|l|}{ Milltown School District, Middlesex County } \\
\hline Parkview Elementary, Milltown & 290 & 75 & Pre-K, K-3 & Parental backpack survey \\
\hline \multicolumn{5}{|l|}{ Netcong School District, Morris County } \\
\hline Netcong Elementary School, Netcong & 298 & 37 & $\mathrm{~K}-3,5,7$ & Parental backpack survey \\
\hline \multicolumn{5}{|c|}{ New Brunswick Public School District, Middlesex County } \\
\hline Lincoln School, New Brunswick & 742 & 187 & Pre-K, K-8 & Parental backpack survey \\
\hline $\begin{array}{l}\text { Lord Stirling Community School, New } \\
\text { Brunswick }\end{array}$ & 708 & 57 & Pre-K, K-5 & Parental backpack survey \\
\hline Paul Robeson School, New Brunswick & 490 & 101 & Pre-K, K-5 & Parental backpack survey \\
\hline Roosevelt School, New Brunswick & 1,025 & 71 & Pre-K, K-5 & Parental backpack survey \\
\hline \multicolumn{5}{|c|}{ Hopewell Valley Regional School District, Mercer County } \\
\hline Stony Brook Elementary, Pennington & 490 & 78 & $\mathrm{~K}-5$ & Parental backpack survey \\
\hline \multicolumn{5}{|l|}{ Tenafly Public Schools, Bergen County } \\
\hline Mackay Elementary School, Tenafly & 356 & 186 & $\mathrm{~K}-5$ & Parental backpack survey \\
\hline Maugham Elementary School, Tenafly & 388 & 109 & $\mathrm{~K}-5$ & Parental backpack survey \\
\hline Smith Elementary School, Tenafly & 369 & 106 & $\mathrm{~K}-5$ & Parental backpack survey \\
\hline Stillman Elementary School, Tenafly & 368 & 132 & $\mathrm{~K}-5$ & Parental backpack survey \\
\hline Tenafly Middle School, Tenafly & 828 & 156 & $6-8$ & Parental backpack survey \\
\hline \multicolumn{5}{|c|}{ Trenton Public School District, Mercer County } \\
\hline Dunn Middle School, Trenton & 590 & 43 & $6-8$ & $\begin{array}{l}\text { Surveys handed out during } \\
\text { parent-teacher conferences }\end{array}$ \\
\hline \multicolumn{5}{|c|}{ Brick Township Public Schools, Ocean County } \\
\hline Midstreams Elementary School, Brick & 576 & 117 & $1-6$ & $\begin{array}{l}\text { Half were parental backpack } \\
\text { survey, and half were mailed } \\
\text { to parents with return } \\
\text { envelope to mail back }\end{array}$ \\
\hline \multicolumn{5}{|l|}{ Ridgewood Public Schools, Bergen County } \\
\hline $\begin{array}{l}\text { George Washington Middle School, } \\
\text { Ridgewood }\end{array}$ & 628 & 155 & $6-8$ & Online survey link e-mailed \\
\hline Hawes Elementary, Ridgewood & 408 & 51 & $\mathrm{~K}-5$ & Online survey link e-mailed \\
\hline \multicolumn{5}{|c|}{ Camden City Public Schools, Camden County } \\
\hline $\begin{array}{l}\text { Rafael Cordero Molina Elementary School, } \\
\text { Camden }\end{array}$ & 692 & 39 & $\mathrm{~K}-3$ & Parental backpack survey \\
\hline
\end{tabular}

*Pre-K and K refer to pre-kindergarten and kindergarten, respectively; a parental backpack survey consists of handing the survey to the students in class with instructions to deliver it to their parents; it can then be returned by the students or sometimes can be completed online or mailed back. 


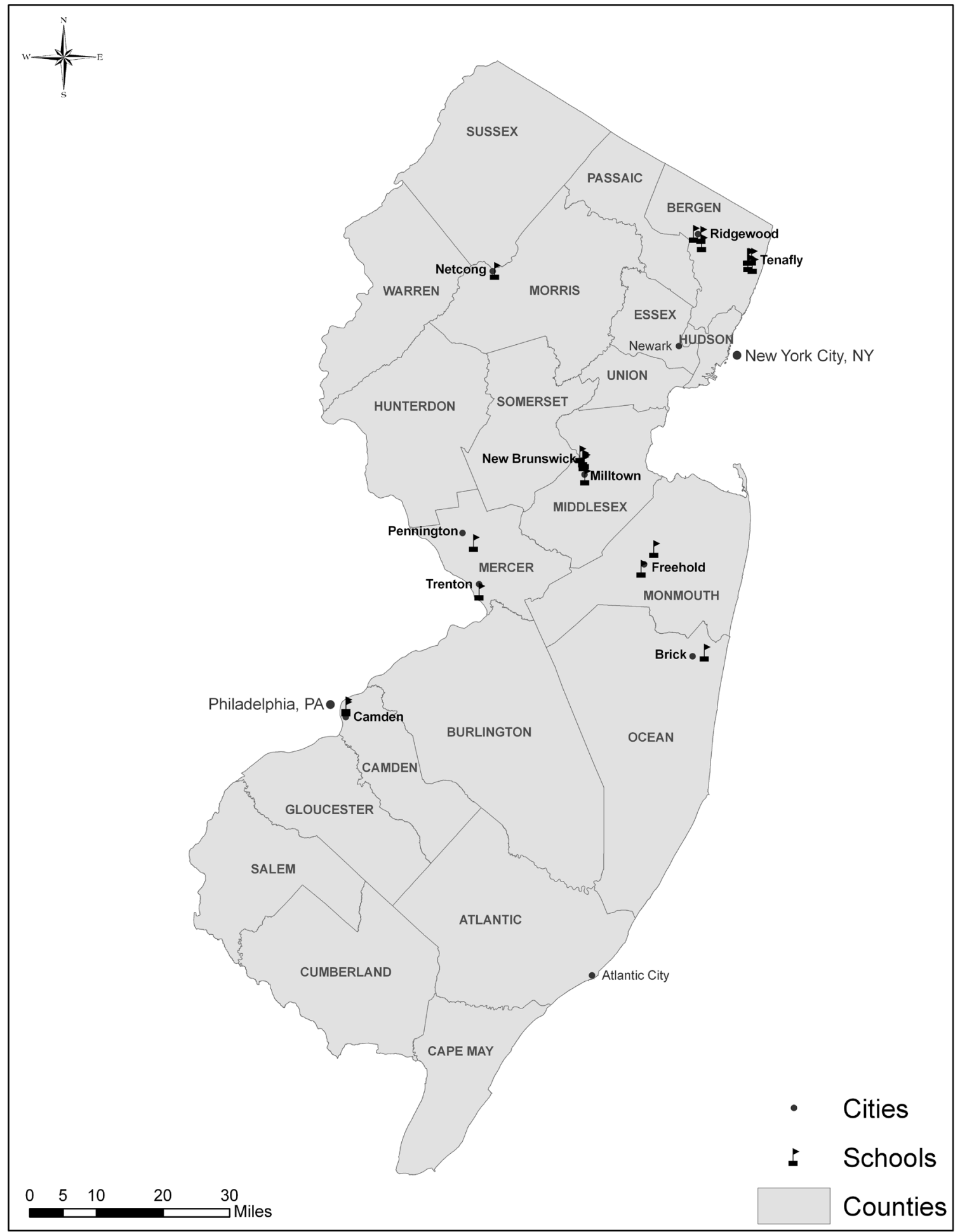

Figure 1: Location of schools in statistical analysis. 


\section{$3 \quad$ Data collection and processing}

From the 19 schools for which we had data, a total of 2118 surveys were received. The key question asked of survey respondents was how their child traveled to school on each day of the week (Monday through Friday). These choices included walk, bicycle, car, carpool, school bus, and other motorized and nonmotorized options. We use the repeated choices reported for each day of the week in our mixed logit model. Two schools in our sample, Milltown and Netcong, do not provide school bus service except in the case of disability. At the time of the survey Netcong also did not allow bicycles to be used to get to school, nor did Midstreams School in Brick Township. In estimating our mode choice model we excluded school bus from the choice set for children at these schools, and we do not include the choice of bicycling in our analysis given the small number of students who used the bicycle mode. In total we are left with 1571 cases (after geo-coding of our sample, discussed below) and 7767 repeated-choice observations. Summary statistics for the variables used in our analysis are listed in Table 2 . These include the attributes associated with unchosen alternatives (e.g., we don't expect a child to walk the maximum time listed in the table). Many of these are based on our geo-coding of the data, which we discuss below.

\subsection{Travel-time estimation of motorized and nonmotorized modes}

We did not ask for household address because of privacy considerations as well as the risk of losing respondents who would not fill out this information, but we did ask for the intersection nearest to their residence. This was subsequently geo-coded, allowing us to estimate travel distance to the school using network distances in ArcGIS. We successfully geo-coded 1769 of our 2118 survey respondents, providing us with travel distances for 83.5 percent of our sample. For some of our respondents we did not have an intersection, but merely one street name. For these we geo-coded the midpoint of the street, as most were short local streets. For these streets we cross-checked the distance against the responses given in the questionnaire on distance to the school; when these were within one-quarter mile of the calculated distance we used the calculated distance. ${ }^{3}$ This provided an additional 135 observations for our data.

We then estimated travel times for each mode in order to estimate alternative-specific travel times in our mode choice model. Stated categorical responses on the travel time by mode for the trip to school (except for school buses) were collected. The categories included 5 minutes or less, 6-9 minutes, 10-14 minutes, 15-20 minutes, and more than 20 minutes. Using the midpoints of these ranges, we regressed these travel times against the estimated distance measures; in the case of walking we held the constant at zero, as there should be no fixed time penalty associated with walking. ${ }^{4}$ The estimated speed results are reasonable for driving but are a bit high for walking and bicycling, as shown in Table 3: Regressions of travel time versus distance with calculated speed.3. As we do not use bicycle choice in our model we disregard this result 5 ; for walking speed we use $2.68 \mathrm{mph}$ as suggested by McDonald $(2008,23-35)$ in the estimates that follow. ${ }^{6}$

\footnotetext{
${ }^{3}$ Although we had self-reported estimates of travel distance to the school, these were in coarse categories; we believe that geo-coding provides more accurate estimates.

${ }^{4}$ Alternatively, cars and bicycles involve some initial start time that involves parking and both accessing and egressing the mode that are captured in the constant.

${ }^{5}$ There were only 32 cases where bicycle was chosen in our data; thus, we excluded this mode from our analysis.

${ }^{6}$ We also estimated models with the faster walk speed of $3.68 \mathrm{mph}$ and found only small differences in parameter values and no differences in statistical significance of estimates.
} 
Table 2: Summary statistics, based on cases.

\begin{tabular}{|c|c|c|}
\hline \multicolumn{2}{|l|}{ Variable } & $\begin{array}{l}\text { Mixed Logit* } \\
\text { (Repeated choice) }\end{array}$ \\
\hline \multicolumn{3}{|c|}{ Continuous variables } \\
\hline \multirow[t]{4}{*}{ Travel time in min. (walk) } & Mean & 15.60 \\
\hline & Std.Dev. & 12.39 \\
\hline & Min & 0.22 \\
\hline & Max & 90.90 \\
\hline \multirow[t]{4}{*}{ Travel time in min. (car) } & Mean & 4.91 \\
\hline & Std.Dev. & 1.81 \\
\hline & Min & 2.67 \\
\hline & Max & 15.91 \\
\hline \multirow[t]{4}{*}{ Grade (walk) ${ }^{7}$} & Mean & 3.53 \\
\hline & Std.Dev. & 2.40 \\
\hline & Min & Pre-K \\
\hline & Max & 8 \\
\hline \multicolumn{3}{|l|}{ Categorical variables (\%) } \\
\hline \multicolumn{2}{|l|}{ Walking encouraged (walk) } & 46.07 \\
\hline \multicolumn{2}{|l|}{ White } & 53.26 \\
\hline \multicolumn{2}{|l|}{ Black or African American } & 3.98 \\
\hline \multicolumn{2}{|l|}{ Hispanic/Latino } & 21.14 \\
\hline \multicolumn{2}{|c|}{ Other Races w/ Asian \& prefer not to answer } & 21.62 \\
\hline \multicolumn{2}{|l|}{ Land use patterns } & \\
\hline \multicolumn{2}{|l|}{ Rural areas } & 6.75 \\
\hline \multicolumn{2}{|l|}{ Active recreation park } & 16.53 \\
\hline \multicolumn{2}{|l|}{ Residential (2 to 4 units/acre) } & 23.25 \\
\hline \multicolumn{2}{|l|}{ Residential ( $\geq 5$ units/acre) } & 53.47 \\
\hline \multicolumn{2}{|l|}{ Connectivity (Adjacent) } & \\
\hline \multicolumn{2}{|l|}{ Traditional and modified grid } & 77.06 \\
\hline \multicolumn{2}{|l|}{ Block size (Face: <500 feet) } & 84.00 \\
\hline \multicolumn{2}{|l|}{ Sidewalks (everywhere $\&$ both sides) } & 51.04 \\
\hline \multicolumn{2}{|l|}{ Traffic facilities } & \\
\hline \multicolumn{2}{|l|}{ Sidewalk width $(>12 \mathrm{ft})$} & 5.42 \\
\hline \multicolumn{2}{|l|}{ Sidewalk width $(6 \sim 12 \mathrm{ft})$} & 33.94 \\
\hline \multicolumn{2}{|l|}{ Sidewalk width $(3 \sim 6 \mathrm{ft})$} & 47.55 \\
\hline \multicolumn{2}{|l|}{ No sidewalk width } & 13.09 \\
\hline \multicolumn{2}{|l|}{ Speed limit $(\leq 25$ miles $)$} & 83.34 \\
\hline \multicolumn{2}{|l|}{ Speed limit ( $\geq 35$ miles) } & 16.66 \\
\hline \multicolumn{2}{|l|}{ Off-street parking capacity ( $<25$ cars) } & 28.75 \\
\hline
\end{tabular}

*Cases $=1571$; Observations $=7767$ (excluding missing values) for Mixed Logit

\footnotetext{
${ }^{7}$ In our dataset, the value of kindergarten is 1,1 st grade is 2,2 nd grade is 3 , etc. When calculating mean value, we acquire 4.53. Because we regard kindergarten as 1 in our dataset, the equivalent mean grade level is 3.53 .
} 
Table 3: Regressions of travel time versus distance with calculated speed.

\begin{tabular}{|l|l|l|l|}
\hline & $\begin{array}{l}\text { Driving time } \\
\text { (mins) }\end{array}$ & $\begin{array}{l}\text { Walking time } \\
\text { (mins) }\end{array}$ & $\begin{array}{l}\text { Bicycling time } \\
\text { (mins) }\end{array}$ \\
\hline Constant & $2.637(18.54)$ & & $3.519(10.17)$ \\
\hline $\begin{array}{l}\text { Distance } \\
\text { (miles) }\end{array}$ & $3.269(21.44)$ & $16.303(59.13)$ & $7.165(16.79)$ \\
\hline Adj. $\mathrm{R}^{2}$ & 0.233 & 0.760 & 0.435 \\
\hline Speed $(\mathrm{mph})$ & $18.35 \mathrm{mph}$ & $3.68 \mathrm{mph}$ & $17.05 \mathrm{mph}$ \\
\hline
\end{tabular}

Coefficient estimates are in minutes/mile; speed is the reciprocal of this multiplied by $60 \mathrm{~min} /$ hour.

\subsection{Urban form and design data}

In addition to student-specific data from parents, we also developed urban form and design measures around each school location. Data were collected via visual observation using both Google StreetView and Bing Maps Bird's Eye; an example is shown for one school in Figure 2. Research by Rundle et al. (2011, 94-100) has found this to be a valid method of collecting data on urban design features. From these images and those of surrounding areas we were able to discern substantial detail on both walkability and design features and land use around the school. ${ }_{8}^{7}$ These included estimates of housing density and the types of housing units around the school, whether ${ }^{8}$ ihe school was situated in a rural area or within a residential area. Connectivity of the sidewalk network near the school was also assessed and categorized. Sidewalk widths were also assessed and roughly categorized, as was the presence of planting strips and trees, all of which have been associated with walkability (Lin and Chang 2010, 867). Speed limits on the primary road were also extracted from Google Street View and Bing Maps Bird's Eye, as well as an estimate of off-street parking capacity in the area around the school.

\subsection{Land-use patterns}

Land-use patterns near the school were also identified by visual observation; these data are classified as Rural (Farm, Forest, Rural Residential), Residential Sprawl ( $<1$ unit/acre), Residential Moderate (2-4 units/acre), Residential Dense ( $>5$ units/acre), Traditional Downtown/Mixed Use, Commercial-Strip Malls, Office Park, and Warehouse/Industrial areas. These are based on whether they are in the immediate vicinity of the school. Generally, urban density is considered a key factor that can increase both walking and bicycling. The mix of uses has generally not been found to be important for school trips, as opposed to other walk trips (Ewing, Schroeer, and Greene 2004, 55-63). Because of correlations in the land-use data, we only use data on estimated residential density.

\footnotetext{
${ }^{8}$ By "around the school" we mean in the immediate vicinity of the school. This was generally a few blocks surrounding the school and sufficient to characterize the walking environment, but had no set distance.
} 


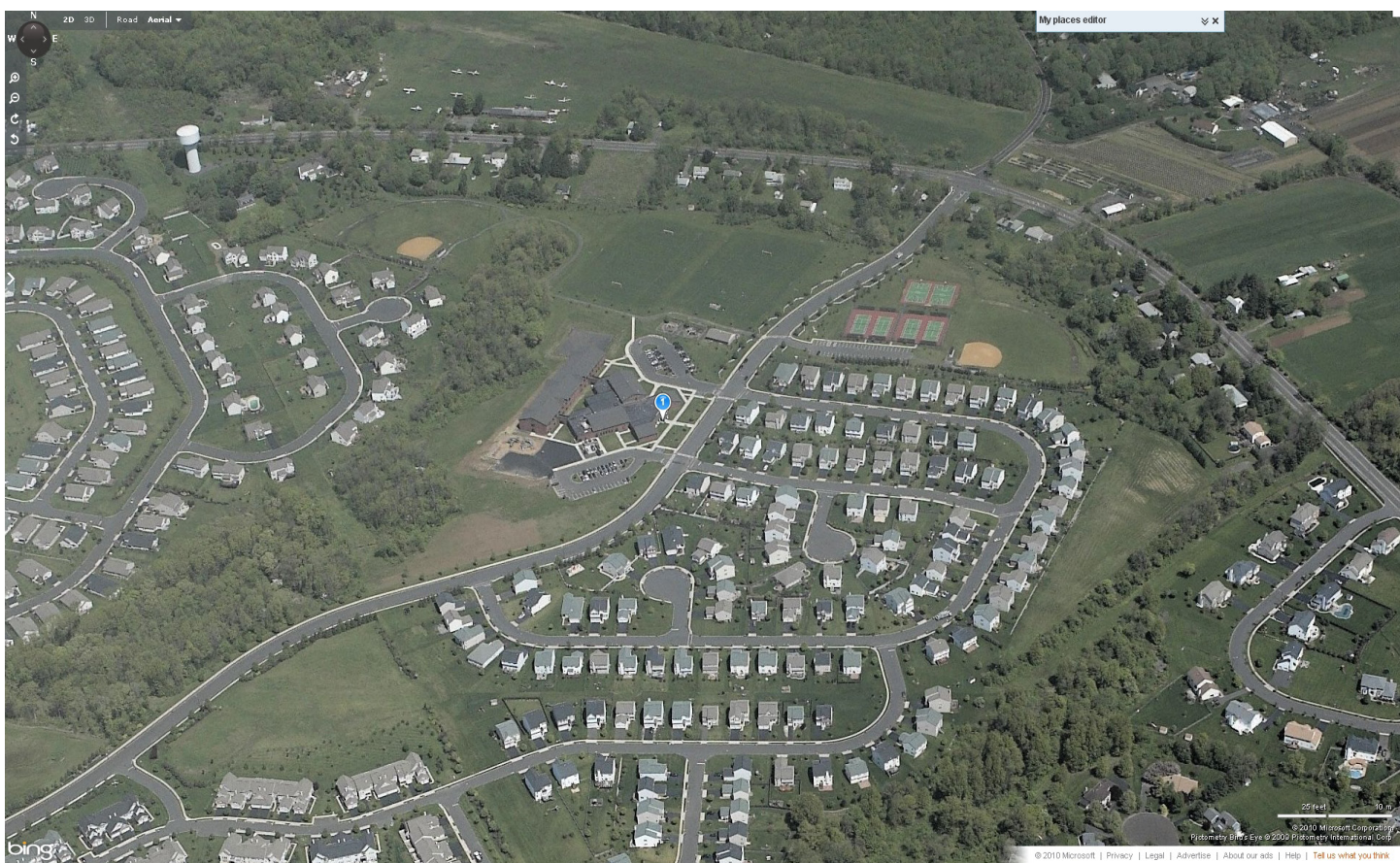

Figure 2: Stony Brook Elementary, 20 Stephenson Road, Pennington, NJ. Bird's Eye View from Bing.com.

\subsection{Connectivity}

Connectivity is another important factor in nonmotorized mode choice (McMillan 2005, 440-456; Cervero and Kockelman 1997, 199-219; Ewing, Schroeer, and Greene 2004, 55-63; McMillan 2007, 69-79; Kitamura, Mokhtarian, and Laidet 1997, 125-158; Moudon et al. 1997, 48-55; Zhu and Lee 2008, 282-290). We have detail on the built environment surrounding each school and in our models we use variables that define the presence of a grid network, sidewalks, and block size when these features are adjacent to the school. Looking at the image in Figure 2, we see that Stony Brook Elementary school is poorly connected with nearby residential areas, separated by a large road in the front and a forested area in the rear, with sidewalks typically on only one side of each residential street with no buffer space from traffic.

\subsection{Urban infrastructure}

We include variables associated with the road infrastructure in the vicinity of the school. These are sidewalk width, speed limits, and off-street parking capacity. Sidewalk width is categorized into four groups: $>12$ feet, 6-12 feet, 3-6 feet, and none. While the complete lack of a sidewalk clearly makes walking unlikely for children, we also examine the size of the sidewalk. We categorize speed limits based on "less than or equal to $25 \mathrm{mph}$ " and "equal to or greater than $35 \mathrm{mph}$." Off-street parking is also measured as a categorical variable with small ( $<25$ vehicles) versus larger lots; the latter would tend to make walking to a school more difficult. There are other traffic facilities, such as marked crosswalks, the presence of traffic signals (including pedestrian signals), street width, medians in the street, and on-street parking. Many of these characteristics were correlated with various other connectivity elements; thus, we excluded them from our statistical analysis. 


\subsection{Other survey questions}

The survey also asked parents if the school encouraged walking or bicycling to get their children to school. Other questions included various socioeconomic variables about the household as well as a list of factors that affect the decision on how the child travels to school.

\section{$4 \quad$ Modeling method}

We estimate a mixed logit model with error components and with random coefficients to test the hypotheses discussed above on factors associated with the choice of mode used to travel to school (Train 2003). According to Train, random coefficients are more suitable for evaluating patterns of choice, while error components are more suitable for predictive purposes. Our goal is to examine patterns of choice, but we present both models; as will be seen, results are similar in terms of direction and significance.

The choice of children's travel to school is determined by the characteristics of the decision-makers' alternatives as well as their attributes; in this case, we assume that parents are the decision makers, although children may play some role in this choice based on their age. As previously mentioned, we have data on the stated choice of travel over one week; in the mixed logit estimates we use the full information of repeated choices for the week.

Using a mixed logit model with error components, we estimate the parameters $\beta_{n}$ associated with decision-maker $n$, representing the tastes of the decision maker. These tastes vary over the decision makers. Since the random taste variation (the unobserved portion of utility) induces correlation between alternatives, this relaxes the restriction of Independence from Irrelevant Alternatives (IIA). The utility can be specified as follows (Coleman et al. 2008, 309-312):

$$
U_{n i}=\beta^{\prime} x_{n i}+\mu_{n i}^{\prime} z_{n i}+\varepsilon_{n i}
$$

The utility, $U$, of individual, $n$, for choice, $i$, is determined by the attributes, $x_{n i}$, with the parameter estimate, $\beta$. The latter two terms represent unobserved utility and serve as the error component that is correlated between alternatives.

For random coefficients, and with panel data, the utility is specified as follows:

$$
U_{\text {nit }}=\beta_{n}^{\prime} x_{n i t}+\varepsilon_{\text {nit }}
$$

In this case, the parameter, $\beta$, varies for each individual, $n$, and $t$ represents repeated choices over time (in our case, over the course of one week). This variation is based on a density function; in this case we assume a normal distribution. From this we can derive a mean coefficient and a standard deviation around that coefficient value.

Given that we are estimating repeated choices over five days, the probability that decision-maker $n$ chooses alternative $i$ among $j$ alternatives in the $t^{\text {th }}$ choice situation is

$$
P_{n i t}=\int \prod_{t}\left(\frac{e^{\beta^{\prime} x_{n i t}}}{\sum_{j=1}^{J} e^{\beta^{\prime} x_{n j t}}}\right) \varnothing(\beta \mid b, W) d \beta
$$

Where $\varnothing(\beta \mid b, W)$ is the normal density of random coefficient $\beta$, which has mean $b$ and covariance $W$, and where $x_{n i t}$ is an explanatory variable for the alternative $i$ that the decision maker $n$ faces in period $t$. Mean $b$ and covariance $W$ represent random taste variation in the population and are derived in our 
estimation results. The model estimated assumes that the random coefficients are normally distributed, as we have no a priori reason to assume another pattern of variation among our decision makers.

Our choice set includes walk, car (family vehicle), carpool, and school bus. We found that estimates did not always converge when the bicycle choice was included; therefore, we omit bicycling from the mode choice model (only 32 students use bicycles as their primary mode). The survey data also include transit and other motorized modes, but as the number of observations for these is small, we also exclude them from our analysis. Two schools do not provide school bus service and for these we constrain the choice set to only three modes. We did not have information on car ownership, so could not constrain the choice of car mode if no car was owned by the household. Table 4 shows the distribution of the modes chosen in our sample. Car is chosen most frequently, followed by walking.

Our travel-time variable is specified as an alternative-specific variable for two of our travel modes, car and walking, calculated from the network distance and our estimates of travel speed by mode. We do not have information on the travel time for carpooling and school buses. School bus availability is included as specific to the school bus mode, since obviously the option of choosing to use a school bus can only be made when school bus service is provided.

Table 4: Distribution of modes chosen.

\begin{tabular}{|l|l|l|l|l|}
\hline Model & Mode & $\begin{array}{l}\text { Case with mode } \\
\text { in choice set }\end{array}$ & $\begin{array}{l}\text { Frequency } \\
\text { selected }\end{array}$ & $\begin{array}{l}\text { Percent } \\
\text { selected }\end{array}$ \\
\hline \hline \multirow{2}{*}{$\begin{array}{l}\text { Mixed logit } \\
\text { (repeated mode } \\
\text { choice) }\end{array}$} & Car & 7,767 & 3,890 & 50.08 \\
\cline { 2 - 5 } & Carpool & 7,767 & 626 & 8.06 \\
\cline { 2 - 5 } & School bus & 1,358 & 596 & 7.67 \\
\cline { 2 - 5 } & Walk & 7,767 & 2,665 & 34.18 \\
\hline
\end{tabular}

We specify the grade the child is in as a walk-mode alternative-specific variable. The parental decision to allow a child to walk to school is partly determined by the age of the child (we do not have child age as a variable, so the grade level proxies for this).

We use the walking encouragement question as an alternative-specific variable for walking. While it is clear that many parents were unaware of whether there was any encouragement, there are clearly schools that appear to encourage walking, such as George Washington Middle School and Henrietta Hawes Elementary School in Ridgewood, compared to others where the affirmative response is low, such as Dunn Middle School in Trenton and Netcong Elementary in Netcong.

We specify household ethnic groups as case-specific and categorize this into four groups-White, African-American, Hispanic/Latino, Other races (usually Asian)/Prefer not to answer (with the latter acting as the reference group in our regressions). We expect children's travel mode to school will differ by ethnic groups, with White being more likely to use cars and minority groups more likely to walk.

We analyzed three different models, including various sets of variables independently. This was done since many of our independent variables were correlated making interpretation of a full model problematic; convergence in mixed logit models can also be difficult when too many independent variables are specified. Thus, we classified variables based on land use, network characteristics, and road and pedestrian infrastructure. We keep mode-specific and socioeconomic variables constant across all specifications. The model results are discussed in the next section.

We estimate mixed logit models using BIOGEME (Bierlaire 2003; Bierlaire 2008). We estimate an error components mixed logit model and a random coefficients model. The latter provides estimates of the heterogeneity of some of the variables — that is, a variance in the parameter estimates for the deci- 
sion makers mode choice. The logit formula, $L_{n i}(\beta)$, is evaluated at different values (weights) of $\beta$ that is drawn from the density $f(\beta)$, and this process is repeated for a large number of draws (Train 2003). The choice probability is derived based on the mean value of the draws. If the number of weights drawn from the density increases, estimating random coefficients will be more accurate but the computation time will increase. In estimating the model, we calculated 1000 draws from the density on the basis of Halton sequences (Train 2003; Bierlaire 2009). The calculated gradient vector never reaches zero (Train 2003). We use a maximum gradient of 0.0001 to determine convergence for the model (Bierlaire 2009). Robust standard errors are derived from the mixed logit model; this is needed because of the use of repeated choices and the clustering of the data around schools. We report the robust t-statistics for the mixed logit model.

\section{$5 \quad$ Results and discussion}

Model results are displayed in Table 5, for models with land-use variables, Table 6 for models with road-connectivity variables, and Table 7 for models with various road-infrastructure variables. The first column displays the error components model and the second column shows results for the random coefficients model. We note any differences in terms of statistical significance between these models. As we are using these models to test hypotheses and not to make predictions, we are less concerned about minor differences in estimated coefficient values. The random coefficients models have higher $\log$-likelihoods for the models in Table 6 and Table 7, suggesting a superior model fit. The difference in log-likelihood is barely distinguishable for the model in Table 5 .

In all our models we find that travel time is negative and statistically significant (at a 99 percent confidence level) for both the car and walk modes (we did not have information on travel times for carpools and school buses). We would expect the magnitude of the parameter estimate to be larger for walking, representing some unmeasured factor that makes walking more onerous, but in almost all cases, we find that the parameter estimate is smaller, suggesting that the time devoted to walking is less onerous for the decision maker compared to driving. This result differs from McDonald (2008, 23-35) and Sidhartan et al. (2011, 78-86), both who found a larger (negative) coefficient on time spent walking. Both studies used National Household Travel Survey (NHTS) data, with the latter study using the oversample for the Los Angeles region. McDonald (2008, 23-35) did not include any detail on urban form and design characteristics at the school, while Sidhartan et al. (2011, 78-86) included an accessibility measure for retail employment. While the length of the trip will clearly influence the trade-off of whether to walk or drive, our result is enlightening and may be due to the different travel-time constraints associated with school trips. The time spent walking is the child's time (unless accompanied by a caregiver), while the time spent driving affects the caregiver and may be part of a more complex time-constrained trip.

We also find that our parameter for the child's grade is positive and statistically significant, implying that older children are more likely to walk to school, as expected and as found in other studies (McDonald 2008, 23-35; Sidhartan et al. 2011, 78-86; Mitra, Buliung, and Roorda 2010, 150-159; McDonald 2008, 324-331). We also find that those parents who believe the school encourages walking are more likely to have children who walk to school. This is a potentially endogenous variable, as it may be that those parents who allow their children to walk are most aware that the school encourages walking, so it is not possible to conclude whether this is a policy variable that can influence behavior.

Each model includes control variables for household ethnicity. Our reference variable for these is "other races/Asian" and those who did not answer (the latter is 5.2 percent of our sample). ${ }^{9}$ Results tend to vary slightly between the three models. Hispanics appear to not drive their children to school, or if they do, they carpool.

\footnotetext{
${ }^{9}$ About 16 percent of the sample were Asian. We grouped these with those who did not report their ethnicity, as the mode choice proportions were similar. This avoided our having to drop about 5 percent of the sample because of missing data.
} 
In some models, Whites also have a slightly higher propensity to carpool relative to driving, while African-Americans have a positive coefficient for walking and for school bus use, and less for driving and carpooling. In general, this result suggests an income effect, as minority populations in the schools surveyed tended to have lower incomes. Results in other studies also tend to be inconclusive; McDonald (2008, 324-331) found Latinos more likely to walk in one analysis, but not in another, using NHTS data for both (McDonald 2008, 23-35). We suspect that the lack of consistent results for these control variables across studies may be due to correlations between the different land use and urban design variables included or excluded in each model; that is, within our sample there are clearly different proportions of each ethnic group living in each school area.

Our key variables of interest are those that measure various land use, urban form, and design features near each school. The discussion that follows focuses on each model in turn; we emphasize the benefits of the mixed logit model estimates on the heterogeneity of the sample and how this provides additional behavioral information. There are some minor differences between the error components and random coefficients models, and we discuss the likely reasons for this.

Table 5 includes categorical variables for residential density near the school, proxying for land use. These include two levels of residential density, all relative to low density — generally rural land use. The random coefficients model estimates demonstrate the heterogeneity in our sample. The parameters for residential density (2-4 units/acre) imply that 43.6 percent of decision makers are not always influenced by density in their choice to walk; the mean value for this parameter is not distinguishable from zero, and the impact is likely cancelled out by the large taste variation. However, for residential density greater than 5 units/acre, the coefficient is significant, with the standard deviation not being significant, suggesting a threshold effect associated with density and walking to school.

There is similar random taste variation in the parental choice with respect to a child's travel to school by carpool. This may be related to parental preference for carpooling independent of urban density and walking-friendly environments.

One variable differs in the error components version of this model. The bus-specific variable for residential density between 2-4 units/acre is negative and statistically significant, as opposed to a lower level of significance in the random coefficients model. The carpool and walk coefficients for this variable are not statistically significant while they show a significant standard deviation in the random coefficients model, suggesting a distinct pattern of heterogeneity among respondents. This shows the additional information the random coefficients model provides.

We examine various measures of connectivity with a dummy variable representing whether there is a traditional or modified grid (relative to no grid), which we expect to be associated with walking. A variable for block sizes of less than $500 \mathrm{ft}$. versus those greater than $500 \mathrm{ft}$. is included; smaller block sizes are assumed to increase walking. For sidewalks, our dummy variable represents whether they are everywhere and on both sides of the street. These variables are measured based on their adjacency to the school (as opposed to within the immediate neighborhood). Results are shown in Table 6.

We find that a grid network is associated with a decrease in driving to school; other work that evaluates associations of street connectivity with travel behavior generally finds that a grid network encourages walking and discourages driving (Cervero and Kockelman 1997, 199-219). Walking is found to be more likely, as is using a school bus or carpooling. The school bus coefficient has the largest effect. This result suggests that schools situated in a grid network reduce the likelihood that parents drive their children alone to school. While we can only speculate, this may be due to slower travel speeds in traditional grid networks, making the school bus more attractive relative to being driven. In all cases the standard deviation of the parameter is not statistically significant, suggesting little heterogeneity and taste variation with respect to this variable (the error components model shows a similar result). This is a 
useful finding and demonstrates that the street layout is an important consideration for reduced driving.

Smaller block sizes adjacent to the school have an association with walking and actually have a negative association with school bus use (relative to driving). This suggests that larger block sizes increase driving to school, perhaps making it easier to quickly drop off students near the school; also, large block sizes may make it easier for school buses to access the school, perhaps leading school districts to supply more service. For carpools, however, only the standard deviation is significant in the random coefficients model, while the parameter is positive in the error components model. This suggests that some fraction of parents will carpool children to school most of the time.

Sidewalks near the school are also strongly associated with walking, relative to driving. Sidewalks near the school appear to have a negative association with school bus use; again, this may be because when sidewalks are not present, better school bus service is supplied. Carpool usage again shows substantial taste heterogeneity; the parameter estimate is significant in the error components model while the standard deviation in the random coefficients model is significant. Probably the key conclusion from this is that lack of sidewalks is associated with more driving to school.

Our final model examines the association with various road infrastructure facilities that can either benefit or hinder pedestrians (Table 7). Those schools with larger sidewalk widths in their immediate vicinity are associated with more children walking to school relative to both driving and other modes of travel (carpools show a negative effect relative to driving). First, the magnitude of the coefficient for the walk mode increases as sidewalk width increases, suggesting that the size of the sidewalk makes a difference in the choice to walk; the standard deviation of the coefficient also increases, suggesting some heterogeneity in how this variable affects behavior. The model shows that 17.1 percent and 17.6 percent of decision makers are not affected by sidewalks in their choice of walking mode for sidewalks 12 feet in width and 6-12 feet in width, respectively. This implies that a certain proportion of parents decide upon their child's travel mode independent of the sidewalk width. The error components model also is statistically significant and the parameter increases as the sidewalk width increases. Therefore, this provides evidence that sidewalks perceived as safer (i.e., wider) can influence the choice of walking for children's travel to school; a fraction of parents, however, choose their child's travel mode based on unmeasured preferences rather than this design factor. Carpool and bus coefficients are negative and also show some heterogeneity.

We find that speed limits of $25 \mathrm{mph}$ on the streets near the school have a negative association with walking, albeit only statistically significant in the error components model. School bus and carpool usage also have a negative association with $25 \mathrm{mph}$ streets relative to streets of $35 \mathrm{mph}$ and above (the reference case); coefficients are larger than for the walking mode. This may imply that driving is more efficient when speed limits are higher. One school in our dataset is near a road with a $40 \mathrm{mph}$ speed limit (Park Avenue Elementary School in Freehold); most of the Hispanic students in our sample from this school walk, while the white students are driven or take a school bus. This may be influencing the result on speed limits and suggests that more detail may be needed on how different ethnic groups are constrained in how their children travel to school. ${ }^{10}$

We also include a measure of off-street parking around the school, as large amounts of parking would likely be a deterrent to walking. Relative to larger amounts of off-street parking, we find that a parking capacity of less than about 25 vehicles is positively associated with walking and school bus use relative to driving. On the other hand, carpool use is greater, perhaps reflecting that a large parking lot makes it easier to drop students off; this variable was not significant in the error components model. We also tested various other infrastructure features, such as the presence of traffic signals, crosswalks, and medians, and found no statistically significant associations; these results were not included in the final

\footnotetext{
${ }^{10}$ For example, we did not have information on whether a car was available for the trip to school and could not constrain the choice set accordingly.
} 
model.

For the most part, these results support the hypothesis that various network connectivity and urban street design components have an association with parents allowing their children to walk to school. Our strongest results are for our network connectivity variable, which is associated with both walking, carpooling, and school bus use. Land-use patterns (proxied by residential density) appear to also exhibit the hypothesized effect of increasing residential density having an association with increased walking. Of the infrastructure variables, wider sidewalks also have a strong association with walking to school. Other variables included in our models — travel time, grade of child, and walking encouragement by the school—have the expected relationships. Our household ethnicity controls do not show consistent results, perhaps due to the distribution of different groups between schools and interactions with the urban design features around each school. 
Table 5: Model 1 (Mixed logit with land-use patterns).

\begin{tabular}{|c|c|c|c|c|c|}
\hline \multirow[t]{2}{*}{ Variables (Alternatives) } & & \multicolumn{2}{|c|}{$\begin{array}{l}\text { Mixed Logit } \\
\text { (error components) }\end{array}$} & \multicolumn{2}{|c|}{$\begin{array}{l}\text { Mixed Logit } \\
\text { (random coefficients) }\end{array}$} \\
\hline & & Coefficient & Robust t-test & Coefficient & Robust t-test \\
\hline School bus (Constant) & & $-3.050^{* * *}$ & -7.55 & $-2.330^{* * *}$ & -11.58 \\
\hline Carpool (Constant) & & $-4.340^{* * *}$ & -9.80 & $-3.400^{* * *}$ & -16.60 \\
\hline Walk (Constant) & & $-1.080^{* * *}$ & -6.07 & $-0.900^{* * *}$ & -5.54 \\
\hline Travel time (Car) & & $-0.258^{* * *}$ & -6.35 & $-0.194^{* * *}$ & -9.44 \\
\hline Travel time (Walk) & & $-0.162^{* * *}$ & -20.96 & $-0.155^{* * *}$ & -24.26 \\
\hline Grade (Walk) & & $0.120^{* * *}$ & 8.65 & $0.121^{* * *}$ & 8.70 \\
\hline Walk encouraged (Walk) & & $0.902^{* * *}$ & 14.77 & $0.900^{* * *}$ & 14.92 \\
\hline \multicolumn{6}{|l|}{ Household ethnic group } \\
\hline White (Bus) & & $1.720^{* * *}$ & 7.74 & $1.400^{* * *}$ & 8.75 \\
\hline White (Carpool) & & $0.837^{* * *}$ & 5.27 & $0.601^{* * *}$ & 4.13 \\
\hline White (Walk) & & $-0.150^{*}$ & -1.99 & $-0.151^{* *}$ & -2.01 \\
\hline Black (Bus) & & $2.750^{* * *}$ & 6.10 & $2.110^{* * *}$ & 6.86 \\
\hline Black (Carpool) & & 0.044 & 0.11 & 0.015 & 0.03 \\
\hline Black (Walk) & & $0.540^{* * *}$ & 3.30 & $0.523^{* * *}$ & 3.11 \\
\hline Hispanic (Bus) & & $2.990^{* * *}$ & 8.45 & $2.460^{* * *}$ & 9.55 \\
\hline Hispanic (Carpool) & & $1.530^{* * *}$ & 7.57 & $1.410^{* * *}$ & 8.15 \\
\hline Hispanic (Walk) & & $1.530^{* * *}$ & 15.95 & $1.530^{* * *}$ & 15.98 \\
\hline \multicolumn{6}{|l|}{ Land-use patterns } \\
\hline Residential: 2 to 4 units/acre (Bus) & $\begin{array}{l}\text { Mean } \\
\text { Std. Dev. }\end{array}$ & $-0.622^{* *}$ & -2.24 & $\begin{array}{l}-0.338 \\
0.055\end{array}$ & $\begin{array}{l}-1.60 \\
0.47\end{array}$ \\
\hline Residential: 2 to 4 units/acre (Carpool) & $\begin{array}{l}\text { Mean } \\
\text { Std. Dev. }\end{array}$ & -0.161 & -1.02 & $\begin{array}{l}-1.630^{*} \\
2.570^{* *}\end{array}$ & $\begin{array}{l}-1.74 \\
2.80\end{array}$ \\
\hline Residential: 2 to 4 units/acre (Walk) & $\begin{array}{l}\text { Mean } \\
\text { Std. Dev. }\end{array}$ & 0.128 & 1.24 & $\begin{array}{l}0.110 \\
0.685^{* *}\end{array}$ & $\begin{array}{l}0.93 \\
2.17\end{array}$ \\
\hline Residential: $>5$ units/acre (Bus) & $\begin{array}{l}\text { Mean } \\
\text { Std. Dev. }\end{array}$ & $0.442^{* *}$ & 2.14 & $\begin{array}{l}0.428^{* *} \\
0.030\end{array}$ & $\begin{array}{l}2.61 \\
0.91\end{array}$ \\
\hline Residential: $>5$ units/acre (Carpool) & $\begin{array}{l}\text { Mean } \\
\text { Std. Dev. }\end{array}$ & $-0.393^{* *}$ & -2.38 & $\begin{array}{l}-0.224^{*} \\
0.124\end{array}$ & $\begin{array}{l}-1.75 \\
0.60\end{array}$ \\
\hline Residential: >5 units/acre (Walk) & $\begin{array}{l}\text { Mean } \\
\text { Std. Dev. }\end{array}$ & $0.160^{*}$ & 1.67 & $\begin{array}{l}0.167^{*} \\
0.006\end{array}$ & $\begin{array}{l}1.75 \\
0.18\end{array}$ \\
\hline Error components (Bus/Car) & $\begin{array}{l}\text { Mean } \\
\text { Std. Dev. }\end{array}$ & $\begin{array}{l}0 \\
1.390^{* * *}\end{array}$ & $\begin{array}{l}- \\
4.82\end{array}$ & & \\
\hline Error components (Carpool/Car) & $\begin{array}{l}\text { Mean } \\
\text { Std. Dev. }\end{array}$ & $\begin{array}{l}0 \\
0.152^{*}\end{array}$ & $\begin{array}{l}- \\
1.71\end{array}$ & & \\
\hline Error components (Walk/Car) & $\begin{array}{l}\text { Mean } \\
\text { Std. Dev. }\end{array}$ & $\begin{array}{l}0 \\
0.058\end{array}$ & $\begin{array}{l}- \\
0.56\end{array}$ & & \\
\hline Number of observations & & & 7,767 & & 7,767 \\
\hline Number of individuals & & & 1,571 & & 1,571 \\
\hline Final log-likelihood & & & 138.24 & & 138.29 \\
\hline Likelihood ratio test & & & 70.71 & & 570.60 \\
\hline Rho-squared & & & 0.312 & & 0.312 \\
\hline Adjusted rho-squared & & & 0.309 & & 0.309 \\
\hline
\end{tabular}

Base alternative (car); reference for household ethnic group: other races, Asian, and prefer not to answer; reference for land-use patterns is rural areas.

*** $\mathrm{p}<0.01,{ }^{* *} \mathrm{p}<0.05,{ }^{*} \mathrm{p}<0.1$ 
Table 6: Model 2 (Mixed logit with the components of connectivity adjacent to the school).

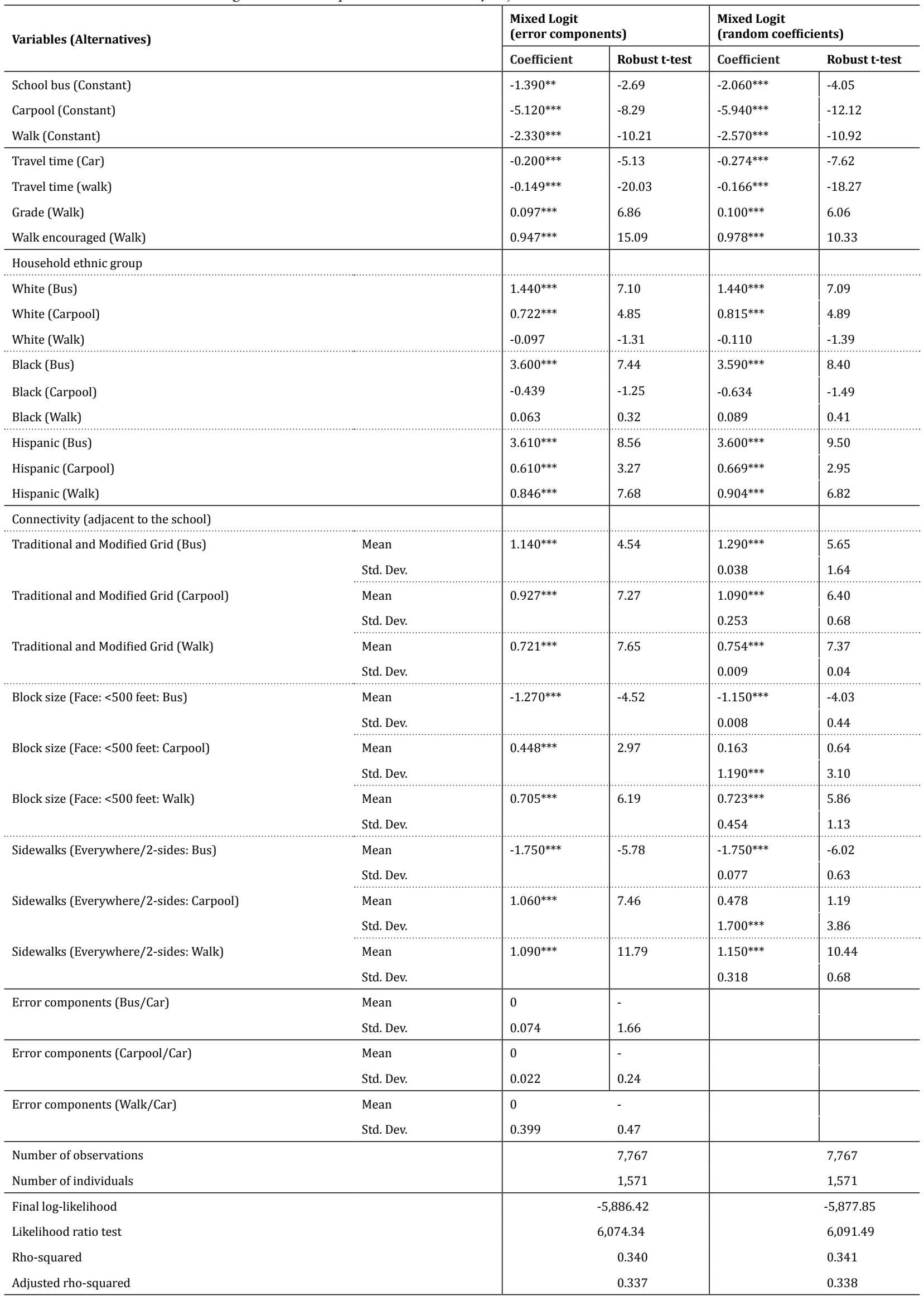

Base alternative (car); reference for household ethnic group: other races, Asian, and prefer not to answer. 
Table 7: Model 3 (Mixed logit with traffic facilities).

\begin{tabular}{|c|c|c|c|c|c|}
\hline \multirow{2}{*}{ Variables (Alternatives) } & & \multicolumn{2}{|c|}{$\begin{array}{l}\text { Mixed Logit } \\
\text { (error components) }\end{array}$} & \multicolumn{2}{|c|}{$\begin{array}{l}\text { Mixed Logit } \\
\text { (random coefficients) }\end{array}$} \\
\hline & & Coefficient & Robust t-test & Coefficient & Robust t-test \\
\hline School bus (Constant) & & -0.039 & -0.12 & $-0.716^{* *}$ & -2.31 \\
\hline Carpool (Constant) & & $-4.440^{* * *}$ & -7.68 & $-4.030^{* * *}$ & -11.00 \\
\hline Walk (Constant) & & $-1.320^{* * *}$ & -6.36 & $-1.460^{* * *}$ & -7.03 \\
\hline Travel time (Car) & & $-0.295^{* * *}$ & -5.63 & $-0.377^{* * *}$ & -9.16 \\
\hline Travel time (Walk) & & $-0.169^{* * *}$ & -17.59 & $-0.199 * * *$ & -8.87 \\
\hline Grade (Walk) & & $0.079^{* * *}$ & 5.11 & $0.083^{* * *}$ & 4.17 \\
\hline Walk encouraged (Walk) & & $0.930^{* * *}$ & 14.47 & $1.020^{* * *}$ & 5.39 \\
\hline \multicolumn{6}{|l|}{ Household ethnic group } \\
\hline White (Bus) & & $0.661^{* * *}$ & 2.93 & $0.604^{* *}$ & 2.80 \\
\hline White (Carpool) & & $0.798^{* * *}$ & 4.74 & $0.915^{* * *}$ & 3.92 \\
\hline White (Walk) & & -0.118 & -1.57 & -0.140 & -1.50 \\
\hline Black (Bus) & & $2.190^{* * *}$ & 5.39 & $1.830^{* * *}$ & 5.26 \\
\hline Black (Carpool) & & -0.014 & -0.03 & -0.213 & -0.33 \\
\hline Black (Walk) & & $0.453^{* *}$ & 2.72 & $0.537^{* *}$ & 2.72 \\
\hline Hispanic (Bus) & & $2.060^{* * *}$ & 5.59 & $1.920^{* * *}$ & 5.44 \\
\hline Hispanic (Carpool) & & $1.610^{* * *}$ & 7.13 & $2.280^{* * *}$ & 6.43 \\
\hline Hispanic (Walk) & & $1.300^{* * *}$ & 12.46 & $1.500^{* * *}$ & 5.66 \\
\hline \multicolumn{6}{|l|}{ Traffic facilities } \\
\hline Sidewalk width: >12ft (Bus) & $\begin{array}{l}\text { Mean } \\
\text { Std. Dev. }\end{array}$ & -0.219 & -0.17 & $\begin{array}{l}-0.437 \\
14.600^{* * *}\end{array}$ & $\begin{array}{l}-0.05 \\
4.83\end{array}$ \\
\hline Sidewalk width: >12ft (Carpool) & $\begin{array}{l}\text { Mean } \\
\text { Std. Dev. }\end{array}$ & $-6.590^{* * *}$ & -14.78 & $\begin{array}{l}-8.900^{* * *} \\
0.006\end{array}$ & $\begin{array}{l}-25.48 \\
0.97\end{array}$ \\
\hline Sidewalk width: >12ft (Walk) & $\begin{array}{l}\text { Mean } \\
\text { Std. Dev. }\end{array}$ & $1.040^{* * *}$ & 5.38 & $\begin{array}{l}1.200^{* * *} \\
1.260^{* *}\end{array}$ & $\begin{array}{l}4.20 \\
2.75\end{array}$ \\
\hline Sidewalk width: $6 \sim 12 \mathrm{ft}$ (Bus) & $\begin{array}{l}\text { Mean } \\
\text { Std. Dev. }\end{array}$ & -0.246 & -0.63 & $\begin{array}{l}-0.534 \\
0.071\end{array}$ & $\begin{array}{l}-1.62 \\
0.96\end{array}$ \\
\hline Sidewalk width: $6 \sim 12 \mathrm{ft}$ (Carpool) & $\begin{array}{l}\text { Mean } \\
\text { Std. Dev. }\end{array}$ & 0.155 & 0.81 & $\begin{array}{l}-0.971^{* *} \\
2.330^{* * *}\end{array}$ & $\begin{array}{l}-2.13 \\
5.11\end{array}$ \\
\hline Sidewalk width: $6 \sim 12 \mathrm{ft}$ (Walk) & $\begin{array}{l}\text { Mean } \\
\text { Std. Dev. }\end{array}$ & $0.945^{* * *}$ & 7.32 & $\begin{array}{l}0.939^{* * *} \\
1.010^{*}\end{array}$ & $\begin{array}{l}6.62 \\
1.97\end{array}$ \\
\hline Sidewalk width: $3 \sim 6 \mathrm{ft}$ (Bus) & $\begin{array}{l}\text { Mean } \\
\text { Std. Dev. }\end{array}$ & $-1.550^{* * *}$ & -4.17 & $\begin{array}{l}-1.820^{* * *} \\
0.061\end{array}$ & $\begin{array}{l}-5.66 \\
0.55\end{array}$ \\
\hline Sidewalk width: $3 \sim 6 \mathrm{ft}$ (Carpool) & $\begin{array}{l}\text { Mean } \\
\text { Std. Dev. }\end{array}$ & $-0.373^{*}$ & -1.89 & $\begin{array}{l}-5.590^{* * *} \\
5.370^{* * *}\end{array}$ & $\begin{array}{l}-3.55 \\
4.62\end{array}$ \\
\hline Sidewalk width: $3 \sim 6 \mathrm{ft}$ (Walk) & $\begin{array}{l}\text { Mean } \\
\text { Std. Dev. }\end{array}$ & $0.427^{* * *}$ & 3.76 & $\begin{array}{l}0.388^{* *} \\
0.792\end{array}$ & $\begin{array}{l}2.30 \\
0.92\end{array}$ \\
\hline Speed limits: 25 Miles (Bus) & $\begin{array}{l}\text { Mean } \\
\text { Std. Dev. }\end{array}$ & $-2.950^{* * *}$ & -6.15 & $\begin{array}{l}-2.320^{* * *} \\
0.014\end{array}$ & $\begin{array}{l}-7.74 \\
0.49\end{array}$ \\
\hline Speed limits: 25 Miles (Carpool) & $\begin{array}{l}\text { Mean } \\
\text { Std. Dev. }\end{array}$ & -0.305 & -1.65 & $\begin{array}{l}-0.965^{* * *} \\
0.167\end{array}$ & $\begin{array}{l}-3.30 \\
0.58\end{array}$ \\
\hline Speed limits: 25 Miles (Walk) & $\begin{array}{l}\text { Mean } \\
\text { Std. Dev. }\end{array}$ & $-0.209^{*}$ & -1.97 & $\begin{array}{l}-0.194 \\
0.030\end{array}$ & $\begin{array}{l}-1.53 \\
0.25\end{array}$ \\
\hline Off-street parking cap.: $<25$ (Bus) & $\begin{array}{l}\text { Mean } \\
\text { Std. Dev. }\end{array}$ & $2.340^{* * *}$ & 7.77 & $\begin{array}{l}2.460^{* * *} \\
0.277\end{array}$ & $\begin{array}{l}9.12 \\
0.33\end{array}$ \\
\hline Off-street parking cap.: $<25$ (Carpool) & $\begin{array}{l}\text { Mean } \\
\text { Std. Dev. }\end{array}$ & -0.136 & -0.86 & $\begin{array}{l}-0.600^{* *} \\
0.214\end{array}$ & $\begin{array}{l}-2.05 \\
1.48\end{array}$ \\
\hline Off-street parking cap.: $<25$ (Walk) & $\begin{array}{l}\text { Mean } \\
\text { Std. Dev. }\end{array}$ & $0.398^{* * *}$ & 5.37 & $\begin{array}{l}0.406^{* * *} \\
0.004\end{array}$ & $\begin{array}{l}3.89 \\
0.22\end{array}$ \\
\hline
\end{tabular}




\begin{tabular}{|c|c|c|c|c|c|}
\hline \multirow[t]{2}{*}{ Variables (Alternatives) } & & \multicolumn{2}{|c|}{$\begin{array}{l}\text { Mixed Logit } \\
\text { (error components) }\end{array}$} & \multicolumn{2}{|c|}{$\begin{array}{l}\text { Mixed Logit } \\
\text { (random coefficients) }\end{array}$} \\
\hline & & Coefficient & Robust t-test & Coefficient & Robust t-test \\
\hline \multirow[t]{2}{*}{ Error components (Bus/Car) } & Mean & 0 & - & & \\
\hline & Std. Dev. & $0.221^{*}$ & -1.79 & & \\
\hline Error components (Carpool/Car) & Mean & 0 & - & & \\
\hline \multirow[t]{2}{*}{ Error components (Walk/Car) } & Mean & 0 & - & & \\
\hline & Std. Dev. & $1.510^{* * *}$ & 4.12 & & \\
\hline \multicolumn{2}{|l|}{ Number of observations } & & 7,767 & & 7,767 \\
\hline \multicolumn{2}{|l|}{ Number of individuals } & & 1,571 & & 1,571 \\
\hline \multicolumn{2}{|l|}{ Final log-likelihood } & \multicolumn{2}{|c|}{$-5,840.43$} & & $-5,808.08$ \\
\hline \multicolumn{2}{|l|}{ Rho-squared } & \multicolumn{2}{|r|}{0.346} & & 0.349 \\
\hline \multicolumn{2}{|l|}{ Adjusted rho-squared } & \multicolumn{2}{|r|}{0.342} & & 0.344 \\
\hline
\end{tabular}

Base alternative (car); reference for household ethnic group: other races, Asian, and prefer not to answer; references for infrastructure: no sidewalk, $35 \mathrm{mph}$ speed limits, parking capacity $>25$.

\section{Conclusions}

We have presented results from a mode choice analysis of how children travel to a sample of schools in New Jersey. Our basic results suggest that various network design, infrastructure, and land-use features that result in what are considered more walkable features have an association with walking. The existence of a sidewalk network, the size of the sidewalks, and the existence of grid networks in particular tend to be associated with less driving and more walking. Much of the research in this area has found the same result, although Mitra (2012, 1-23) reports some inconsistencies between study results.

One contribution of our work beyond that of other school trip studies is the use of a mixed logit model. This allows us to examine the heterogeneity in the sample. Our results clearly show that there is random taste variation in the sample that has not been controlled for in previous studies. Some fixed proportion of the decision makers in our sample are not affected by pedestrian-friendly design and infrastructure in making the decision to allow their children to walk to school. A better understanding of parental attitudes and methods to measure those attitudes might provide a means to fully understand these effects. The framework suggested by Mitra $(2012,1-23)$ includes attitudes of households that should be controlled for in future studies.

Our study suffers from some limitations. First, our results are associative. We cannot provide strong conclusions as to whether infrastructure interventions will increase walking activity. While our results are theoretically consistent with how we expect decision makers to react, our methods are not adequate for drawing causal interpretations. Another issue is that we cannot deal with the endogeneity of school choice - that is, parents who want their children to walk to school chose to live near schools their children can walk to. This would require detailed information on residential location choice, which is not available. An additional limitation is that the sampling strategy has not resulted in a random sample, either of schools or parents in each school. While some individual schools achieved adequate response rates, we would expect those parents that are more involved with the school and more active in their children's education to be more likely to respond. We were unable to have any follow up to increase the sampling rate. Likewise, the schools self-selected into the sample, either because they were seeking state funding or had an active Safe Routes to School program; despite this, some of the schools do not have 
proactive policies to increase active commuting to school (e.g., some schools did not allow bicycling). Difficulties with gaining access to school samples suggest that randomized sampling focused on specific neighborhoods might be needed, although this will capture many residents with no children attending school, and thus is a costly approach.

Future research in this area will need to investigate actual interventions at a random sample of schools. These interventions can include educational efforts to increase walking as well as infrastructure changes to increase the safety of walking. A difficulty with any study of this type is accessing the sample of children and satisfying any privacy concerns of parents. These issues are, however, critical in seeking not only to increase the activity of children to tackle obesity, but also to reduce driving and its environmental impacts.

\section{Acknowledgements}

This research was funded by the New Jersey Department of Transportation Safe Routes to School Program. The authors accept all responsibility for the content of this paper, and the views expressed herein are in no way the views or policy of the New Jersey Department of Transportation. The authors thank Jennifer Rovito, Sean Meehan, and Andrew Besold for research assistance.

\section{References}

Alfonzo, M. A. 2005. To walk or not to walk? The hierarchy of walking needs. Environment and Behavior 37(6): 808-836. http://dx.doi.org/10.1177/0013916504274016.

Bierlaire, M. 2003. BIOGEME: A free package for the estimation of discrete choice models. Proceedings of the 3rd Swiss Transportation Research Conference, Ascona, Switzerland.

- 2008. An Introduction to BIOGEME. Version 1.6 ed. biogeme.epfl.ch.

—. Estimation of Discrete Choice Models with BIOGEME 1.8. Ecole Polytechnique Federale de Lausanne, Lausanne, Switzerland.

Boarnet, M. G., C. L. Anderson, K. Day, T. E. McMillan, and M. Alfonzo. 2005. Evaluation of the California Safe Routes to School legislation: Urban form change and children's active tranportation to school. American Journal of Preventive Medicine 28(2S2): 134-140. http://dx.doi.org/10.1016/j. amepre.2004.10.026.

Cervero, R. and K. Kockelman. 1997. Travel demand and the 3Ds: Density, diversity, and design. Transportation Research D 2(3): 199-219. http://dx.doi.org/10.1016/S1361-9209(97)00009-6.

Coleman, K. J., D. E. Rosenberg, T. L. Conway, J. F. Sallis, B. E. Saelens, L. D. Frank, and K. Cain. 2008. Physical activity, weight status, and neighborhood characteristics of dog walkers. Preventive Medicine 47(3): 309-312. http://dx.doi.org/10.1016/j.ypmed.2008.05.007.

Ewing, R. and R. Cervero. 2001. Travel and the built environment: A synthesis. Transportation Research Record 1780(1): 87-114. http://dx.doi.org/10.3141/1780-10.

Ewing, R., W. Schroeer, and W. Greene. 2004. School location and student travel analysis of factors affecting mode choice. Transportation Research Record: Journal of the Transportation Research Board 1895: 55-63. http://dx.doi.org/10.3141/1895-08.

Frank, L. D., T. L. Schmid, J. F. Sallis, J. Chapman, and B. E. Saelens. 2005. Linking objectively measured physical activity with objectively measured urban form: Findings from SMARTRAQ. American Journal of Preventive Medicine 28(2): 117-125. http://dx.doi.org/10.1016/j.amepre.2004.11.001.

Frank, L. D., J. F. Sallis, B. E. Saelens, L. Leary, K. Cain, T. L. Conway, and P. M. Hess. 2010. The devel- 
opment of a walkability index: Application to the neighborhood quality of life study. British Journal of Sports Medicine 44(13): 924-933. http://dx.doi.org/10.1136/bjsm.2009.058701.

Frank, L. D., J. F. Sallis, T. L. Conway, J. E. Chapman, B. E. Saelens, and W. Bachman. 2006. Many pathways from land use to health: Association between neighborhood walkability and active tranportation, body mass index, and air quality. Journal of the American Planning Association 72(1): 75-87. http://dx.doi.org/10.1080/01944360608976725.

Kerr, J., D. Rosenberg, J. Sallis, B. E. Saelens, L. D. Frank, and T. L. Conway. 2006. Active commuting to school: Associations with environment and parental concerns. Medicine \& Science in Sports \& Exercise 38(4): 787-794. http://dx.doi.org/10.1249/01.mss.0000210208.63565.73.

Kitamura, R., P. L. Mokhtarian, and L. Laidet. 1997. A micro-analysis of land use and travel in five neighborhoods in the San Francisco Bay area. Transportation 24 (2): 125-158. http://dx.doi. org/10.1023/A: 1017959825565.

Lin, J. J. and H. T. Chang. 2010. Built environment effects on children's school travel in Taipai: Independence and travel mode." Urban Studies 47(4): 867-889. http://dx.doi. org/10.1177/0042098009351938.

Manaugh, K. and A. El-Geneidy. 2011. Validating walkability indices: How do different households respond to the walkability of their neighborhood? Transportation Research Part D: Transport and Environment 16(4): 309-315. http://dx.doi.org/10.1016/j.trd.2011.01.009.

McDonald, N. C. 2007. Active transportation to school: Trends among U.S. schoolchildren, 19692001. American Journal of Preventive Medicine 32(6): 509-516. http://dx.doi.org/10.1016/j. amepre.2007.02.022.

- 2008. Children's mode choice for the school trip: The role of distance and school location in walking to school." Transportation 35(1): 23-35. http://dx.doi.org/10.1007/s11116-007-9135-7.

- 2008. Household interactions and children's school travel: The effect of parental work patterns on walking and biking to school. Journal of Transport Geography 16(5): 324-331. http://dx.doi. org/10.1016/j.jtrangeo.2008.01.002.

McMillan, T. E. 2007. The relative influence of urban form on a child's travel mode to school. Transportation Research Part A: Policy and Practice 41 (1): 69-79.

- 2005. Urban form and a child's trip to school: The current literature and a framework for future research. Journal of Planning Literature 19(4): 440-456. http://dx.doi. org/10.1177/0885412204274173.

Mitra, Raktim. 2012. Independent mobility and mode choice for school transportation: A review and framework for future research. Transport Reviews 33(1): 1-23.

Mitra, R., R. N. Buliung, and M. J. Roorda. 2010. Built environment and school travel mode choice in Toronto, Canada. Transportation Research Record: Journal of the Transportation Research Board 2156(1): 150-159. http://dx.doi.org/10.3141/2156-17.

Moudon, A. V., P. M. Hess, M. C. Snyder, and K. Stanilov. 1997. Effects of site design on pedestrian travel in mixed-use, medium-density environments. Transportation Research Record 1578: 48-55.

Pinjari, A. R., N. Eluru, C. R. Bhat, R. M. Pendyala, and E. Spissu. 2008. A joint model of residential neighborhood type choice and bicycle ownership: Accounting for self-selection and unobserved heterogeneity. Transportation Research Record: Journal of the Transportation Research Board 2082(-1): 17-26. http://dx.doi.org/10.3141/2082-03.

Rundle, A. G., M. D. M. Bader, C. A. Richards, K. M. Neckerman, and J. O. Teitler. 2011. Using Google street view to audit neighborhood environments. American Journal of Preventive Medicine 40(1): 94-100. http://dx.doi.org/10.1016/j.amepre.2010.09.034.

Saelens, B. E. and J. F. Sallis. 2007. Neighborhood walkability and the walking behavior of Austra- 
lian adults. American Journal of Preventive Medicine 33(5): 387-395. http://dx.doi.org/10.1016/j. amepre.2007.07.025.

Schlossberg, M., J. Greene, P. P. Phillips, B. Johnson, and B. Parker. 2006. School trips: Effects of urban form and distance on travel mode. Journal of the American Planning Association 72(3): $337-$ 346. http://dx.doi.org/10.1080/01944360608976755.

Sidhartan, R., C. R. Bhat, R. M. Pendyala, and K. G. Goulias. 2011. Model for children's school travel mode choice: Accounting for effects of spatial and social interaction. Transportation Research Record: The Journal of the Transportation Research Board 2213(-1): 78-86. http://dx.doi. org/10.3141/2213-11

Sirard, J. R. and M. E. Slater. 2008. Walking and bicycling to school: A Review. American Journal of Lifestyle Medicine 2(5): 372-396. http://dx.doi.org/10.1177/1559827608320127.

Train, Kenneth. 2003. Discrete Choice Methods with Simulation. Cambridge University Press.

Zhu, X. and B. Lee. 2008. Walkability and safety around elementary schools: Economic and ethnic disparities. American Journal of Preventive Medicine 34(4): 282-290. http://dx.doi.org/10.1016/j. amepre.2008.01.024. 